Communicating Policy Options at the Zero Bound

Lukas Burkhard and Andreas M. Fischer

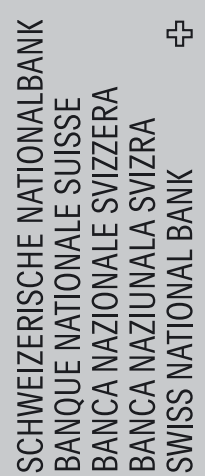

(1)

(4)

(1)

ro

(

$\frac{0}{5}$

ro

C

0

10 
The views expressed in this paper are those of the author(s) and do not necessarily represent those of the Swiss National Bank. Working Papers describe research in progress. Their aim is to elicit comments and to further debate.

ISSN $1660-7716$

๑ 2007 by Swiss National Bank, Börsenstrasse 15, P.0. Box, CH-8022 Zurich 


\title{
Communicating Policy Options at the Zero Bound
}

\author{
October 2007
}

\author{
Lukas Burkhard† and Andreas M. Fischer $\ddagger$
}

\begin{abstract}
This paper examines a special episode in communication practices of the Swiss National Bank (SNB) when short-term interest rates reached the zero bound. A particular feature of SNB communication policy at the time was to talk openly about alternative policy instruments despite the fact that they were never implemented. Non-sterilized FX interventions were frequently mentioned as a potential instrument. We ask how did financial markets respond to the SNB's repeated references of non-sterilized interventions? The empirical results with high frequency data provide strong evidence that SNB intervention references depreciated the domestic currency for several hours. The case study supports the view that communication is an effective tool for monetary policy.
\end{abstract}

Keywords: Exchange Rate, Central Bank Communication, Zero Bound JEL Classification Number: F31, E58

† Swiss National Bank, Postfach, 8022 Zurich, Switzerland email: lukas.burkhard@snb.ch

$\ddagger$ Swiss National Bank, University of Berne, and CEPR, Postfach, 8022 Zurich, Switzerland

email: andreas.fischer@snb.ch

* The authors would like to thank an anonymous referee for helpful comments. Werner Abegg, Rasmus Fatum, Marcel Fratzscher, Ulrich Kohli, Christopher Neely, Michel Peytrignet, Angelo Ranaldo, Marcel Savioz, the IRTA group, and the SNB BB seminar offered helpful remarks and suggestions on an earlier version of the paper. The views expressed in this paper are solely the responsibility of the authors and should not be interpreted as reflecting the views of the Swiss National Bank. 


\section{Introduction}

The empirical literature on communication strategies for exchange rates has until now worked only with broad definitions of verbal interventions. Verbal interventions are statements by central bank officials that either support or undermine the domestic currency without necessarily referring to central bank interventions. Fratzscher (2005, 2006), Jansen and de Haan (2005, 2007), and Fatum and Hutchison (2002) use an indicator function to filter positive and negative statements by ECB officials and others in reference to the euro. The evidence is mixed. Jansen and de Haan (2005), using high frequency exchange rate data, find little or no response, while Fatum and Hutchison (2002), using daily data, identify an asymmetric reaction. Other studies by Beine et al. (2004) and Fratzscher (2005, 2006), using a GARCH specification for daily data, show that verbal interventions reduce exchange rate volatility.

One source for the empirical discrepancy is the verbal intervention indexes. The indexes are constructed using a broad search for newswire reports with reference to specific names of central bank officials and the U.S. dollar or the euro. The selected reports are then interpreted subjectively as being references of currency support or currency neglect. Despite using sim- 
ilar search algorithms and similar samples for the euro, studies by Fratzscher (2005, 2006), Fatum and Hutchison (2002), and Jansen and de Haan (2005) do not work with the same number of verbal interventions. ${ }^{1}$ Further, all supportive references are assumed to generate similar market reactions. No attempt is made to separate weak references from strong references. A possible solution is to narrow the focus on strongly worded statements that make a clear reference to foreign exchange interventions. We set out to do this.

The objective of this paper is to examine the financial market's response to strongly worded statements by central bank officials that make direct reference to foreign exchange interventions (hereafter, intervention references). To make robust statements about such a communication policy, we test the following hypotheses. Do intervention references by central banks sway exchange rates? Is the first reference more important than other same-day reports? Do financial markets respond equally to central bank communication of potential FX interventions under different monetary policy environments? To test these hypotheses, we first construct an index of intervention references

\footnotetext{
${ }^{1}$ For (daily) verbal interventions over the period 1999 to around 2002, Fatum and Hutchison (2002) find 36 statements, Jansen and de Haan (2005) 127 statements, and Fratzscher $(2005,2006) 79$ statements.
} 
based on newswire reports. Next, event study analysis is used to determine whether our narrow definition of intervention references corresponds with high-frequency movements in the exchange rate.

Our empirical analysis examines a special episode between 2002 and 2005 where the Swiss National Bank (SNB) made references on the potential use of FX interventions. The SNB intervention references refer to the unconventional policy of non-sterilized interventions and should be viewed as communicating a new policy option when interest rates are zero. ${ }^{2}$ Our study thus extends the empirical literature by Bernanke and Reinhart (2004) and Bernanke et al. (2004). These studies, which rely on theoretical work by Eggertsson and Woodford (2003) and others, argue that communication is an effective tool in shaping policy expectations when nominal interest rates are close to or equal to zero. Bernanke et al. (2004) provide evidence that

\footnotetext{
${ }^{2}$ Sterilized interventions are a combination of two transactions. The central bank may first purchase foreign-currency denominated bonds and increase the domestic monetary base. The second transaction then sterilizes the first by selling a corresponding quantity of domestic-currency denominated bonds in order to reverse the effects on the monetary base. Non-sterilized interventions involve only the first operation and are regarded as a form of open market operation. Their influence on the exchange rate is not disputed when interest rates are not at the zero bound, whereas sterilized interventions are.
} 
Fed references of policy inclinations about the future path of interest rates are able to move asset prices. Our contribution is to extend the empirical literature on communication effectiveness at the zero bound beyond the United States and Japan to a small open economy setting, Switzerland. ${ }^{3}$

The paper is organized as follows. Section two discusses the intervention references index and the empirical methodology. Section three presents the main empirical results. Section four offers concluding remarks.

\section{Institutional aspects, data, and methodology}

This section begins with institutional aspects of Swiss intervention references. The discussion is important for understanding the SNB's communication strategy during a period when short-term interest rates reached their lower bound. Next, the intervention reference index is presented. Then, a discussion of the empirical methodology based on the event-study approach follows.

\footnotetext{
${ }^{3}$ The Swiss practice of referring to non-sterilized interventions at the zero bound was dismissed by the Federal Reserve and the Bank of Japan as a viable policy option. This was because the legal competence to intervene lies with another institution and the fear that political problems with trade partners could arise, see Bernanke (2002) and Clouse et al. (2000) for the United States and Ito (2004) and Ito and Mishkin (2004) for Japan.
} 


\subsection{Institutional aspects of SNB intervention references}

Since January 2000, the SNB's policy framework may be characterized as inflation forecasting with a floating exchange rate, see Baltensperger et al. (2007). The policy framework includes the following. The main objective of the SNB's monetary policy is price stability. The SNB has no exchange rate objective. To achieve price stability, the SNB sets a target range for the three-month Libor rate. Adjustments to the target range are motivated by the SNB's consensus inflation forecasts. To steer the Libor rate within the target range, the SNB uses the one-week repo as its operational instrument. Within this framework, the exchange rate only matters to the extent that it can threaten price stability to the upside or to the downside.

A mystery about SNB intervention references is, given the SNB's policy framework, why were so many intervention references made between 2002 and 2005? Ever more so, the last SNB intervention was conducted on 30 August 1995. Was the SNB bluffing? Two arguments suggest it was not.

A first motive for frequent intervention references was the need to communicate an alternative policy strategy against a backdrop of deflationary fears and low interest rates. Any intervention in the foreign exchange market would have been conducted with the primary objective to supply the market 
with liquidity and not necessarily to weaken the Swiss franc. ${ }^{4}$ Swiss concerns about deflation increased considerably in the first half of 2003, because economic growth in Switzerland and its neighboring countries was weak, annual inflation measured by the CPI was $0.5 \%$, and the one-week repo rate stood at 0.11\%. The SNB's zero rate policy was frequently compared to the Bank of Japan's, see Bernanke et al. (2004) and Natal (2004). International organizations, such as the IMF and the OECD, also called on the SNB to undertake non-sterilized interventions. ${ }^{5}$ Beginning in October 2002, the tone and the persistence of the SNB references became stronger and lasted well into 2004.

\footnotetext{
${ }^{4}$ While newswire reports often talked about intervention threats, and it was perhaps perceived by market participants as such, the SNB was mostly trying to explain to the public that, even at the zero bound, it had ways to inject liquidity into the market. Buying foreign exchange is just one of these options. Another one would be to buy government bonds, or indeed any type of securities.

${ }^{5}$ See IMF Article IV (2003) page 22, "With conventional policy options now exhausted, further upward pressures on the Swiss franc that led to an unwanted tightening of monetary conditions should be countered by unsterilized intervention". OECD Economic Study 2003 page 11 writes "... given that there is no room for further rate cuts, the Swiss National Bank (SNB) should stand ready to use unorthodox instruments to avoid deflation from becoming entrenched in expectations. In this respect, interventions in the foreign exchange market would be most effective."
} 
Non-sterilized interventions were announced as a potential instrument for Swiss monetary policy. The SNB was determined to assure the public that it still had alternative policy options at its disposal. This meant that the SNB had to augment its communication efforts. One means was to increase the number of intervention references.

A second reason why financial markets may respond to SNB intervention references is past history. FX trader's comments to SNB intervention references frequently mentioned the SNB's episode of "exchange rate management" and its ability to change monetary regimes, see Rich (1990). During this brief episode between 1978 and 1979, monetary targeting was suspended and replaced by an explicit exchange rate target. Svensson (2001) and others have advocated a similar policy for Japan twenty years later.

It may be argued that both explanations sought to "shape policy expectations" for the Swiss franc. They do this by increasing the probability of the event that the SNB will undertake further expansionary measures. Similar explanations are advocated by Bernanke and Reinhart (2004) and Bernanke et al. (2004). They argue that the communication of future policy actions is the only effective tool to influence medium-term expectations when short- 
term rates are close to or equal to zero. ${ }^{6}$ A communication policy at the zero bound needs to convince markets of alternative policy options. It may be argued that (whether intended or unintended) SNB intervention references did this. Several intervention references explicitly state that non-sterilized interventions will augment market liquidity in the medium term. This in turn will increase inflationary expectations, weaken the Swiss franc, and improve real economic activity through higher net exports.

\subsection{Intervention reference index}

To construct our intervention references index, we rely on newswire reports from Factiva. ${ }^{7}$ Three considerations guide the construction of the index. $^{8}$ The first decision defines the information space to be searched. We

\footnotetext{
${ }^{6}$ Bernanke et al. (2004) also consider two other options: increasing the size of the central bank's balance sheet and changing the composition of the central bank's balance sheet. Both of these issues do not apply to the Swiss experience.

${ }^{7}$ Fischer (2006) finds evidence that prior to 1995 the timing of newswire reports of SNB interventions deviated from the official time stamp of the SNB intervention transaction. Despite this weakness, newswire reports are the only source that captures the SNB intervention references and is one of the main sources of information for FX traders.

${ }^{8}$ Boukus and Rosenberg (2006) offer an alternative procedure for translating complex qualitative information into a quantitative index. Their application, based on Latent Semantic Analysis, is used to identify common themes in FOMC minutes. Our objective
} 
restricted ourselves to newswire reports that mention the SNB, with reference to foreign exchange intervention. Each newswire report contains the words "intervention", "intervenes", or "intervening" and was required to have a clear connection with the Swiss franc. A large share of the newswire reports directly quote SNB officials from speeches, interviews, and press releases. ${ }^{9}$ In five instances, we also included newswire statements that interpret SNB intervention references to mean a foreign exchange intervention without direct reference to the original text or direct quotation of the SNB official. ${ }^{10}$ Our filtered search from 1 January 2002 to 31 December 2005 resulted in 304 reports.

A second decision in constructing the intervention reference index is to limit the time range of the newswire reports to normal trading hours for the Swiss franc-euro exchange rate. All newswire reports with a (Zurich) time stamp outside of normal trading hours (i.e., before 8:00 and after 16:00) were excluded. This is done because trading in the CHF/EUR is not continuous differs from this approach in that it seeks to offer a specific definition of verbal interventions and test its stimulus.

${ }^{9}$ We assume that the newswire report responds equally to interviews, speeches and press statements.

${ }^{10}$ An example, dated 18.03.2003, is "Roth tells exporters SNB will not intervene to weaken Swiss franc". 
and we are interested in examining the market's immediate response with intra-daily exchange rate data to a SNB intervention reference. ${ }^{11}$ This left us with 162 news reports.

The last decision involves categorizing the news reports along two dimensions. The first considers whether the intervention references were supportive or neglective. Supportive intervention references are statements by the SNB that mention the possible use of foreign currency purchases to weaken the Swiss franc. Similarly, neglective intervention references are declarations that reject the possible use of foreign interventions.

Next, the supportive and neglective references are divided into three classes: weak, moderate, and strong. Weak supportive (negative) references mention that intervention is currently not a policy issue (interventions are not always effective). Moderate references mention that interventions are a possible option (interventions could have negative consequences), whereas strong references state that the SNB will intervene under specific conditions (interventions have clear negative consequences). Examples of supportive

\footnotetext{
${ }^{11}$ Historically, Fischer and Zurlinden (1999) show that the SNB interventions before 1995 were often around 10:00 and 15:00 (periods when the interbank market is most liquid). About $45 \%$ of the intervention references fell in these hours.
} 
and neglective intervention references are given in Table 1.

Table 2 shows the distribution of the intervention references. They are classified as the number of SNB intervention references for a given day, the number of SNB references, and all intervention references. The latter references include SNB references plus intervention references from various agencies (i.e., IMF, OECD, and Swiss Finance Ministry) and market analysts. These intervention references, which do not necessarily cite official sources, were constructed in the same manner as SNB intervention references. The effectiveness of the two types of intervention references will be tested in the next section.

A striking feature of the distribution in Table 2 is that 89 of the 112 SNB references on intervention are classified as strong and supportive for the 2002 to 2005 period. Apart from the supportive and strong intervention references, the categories of the other intervention references are too few to warrant valid hypothesis testing. The empirical analysis thus will focus primarily on supportive and strong intervention references. This is our variable of interest.

To underscore the special nature of intervention references during the zero interest rate period, three distinct features separate the earlier period from 1996 to 2001. First, unlike in the period marked by deflationary fears 
and zero interest rates, intervention references in the earlier period from 1996 to 2001 always referred to sterilized interventions. Second, intervention talk was sparse during the 1996 to 2001 period (only eight observations of strong and supportive references were identified). Third, the motivation for the intervention references focused on external factors attributed to the euro in the earlier period as opposed to domestic factors attributed to deflationary fears in the later period. In the run up to the euro's introduction in 1999 and after, the SNB and other Swiss institutions expressed concern that the euro would depreciate against the Swiss franc, see Fischer (2002), Rich (2000), and the SNB's press release from 11.12.98.

Figure 1a shows the profile of the intervention reference index (right axis), the mid range of the SNB's target range for the three-month Libor (left axis), and the one-week repo rate from 2002 to 2005 (left axis). The index is plotted such that positive (negative) values represent supportive (neglective) intervention references. To highlight the different categories of intervention references, the value $+1 /-1$ denotes weak, $+2 /-2$ moderate, and $+3 /-3$ strong intervention references. The plot shows that the number of strong and supportive verbal references increased just before the mid point of the SNB target range of the three-month Libor was lowered to 0.25\% in March 2003. 
Similarly, the intensity of the supportive and strong intervention references fell just before the three-month Libor was raised in June 2004.

Figure 1b plots the intervention reference index but now with the Swiss franc-euro exchange rate. The graph shows that the Swiss franc's depreciation, beginning in March 2003, did not respond immediately to the strong and supportive references made in the fall of 2002. Instead, its timing appears to be more correlated with the lowering of short-term interest rates (see Figure 1a). The empirical analysis in section 3 focuses primarily on the question of the extent to which the intervention references supported the Swiss franc's depreciation from March 2003 to January 2004.

The focus on strong and supportive intervention references should reduce subjectivity concerns relating to the transformation of qualitative information into a quantitative index. Several issues merit further discussion, though. The first concerns adequate media coverage of a non G-3 currency and the potential of underreporting, see Fischer (2006). This issue should be less problematic if transparency is high. Many studies have argued that Swiss interventions are transparent. ${ }^{12}$ Hence, it is highly probable that an open

\footnotetext{
${ }^{12}$ See Fischer and Zurlinden (1999), Fischer (2006, 2003), Payne and Vitale (2003), and Pasquarillo (2007).
} 
communication policy also applies to intervention references. As such, a strategy based on newswire reports should guarantee wide coverage. A second issue is wrong reporting and misinterpretation. This may arise through the news agency's misinterpretation of SNB official statements or through our misclassification of newswire reports. The narrow focus on official references in connection with the Swiss franc and foreign exchange interventions, however, should reduce such errors. A third concern is the literature's reliance on code words by central bank officials, see Bernanke et al. (2004). Again, this is less problematic in our study, in that we restrict ourselves to strongly worded statements with reference to foreign exchange interventions. Last, our narrow focus on specific intervention references allows us to identify precisely the exchange rate response. This represents an improvement over indicator procedures used by Kohn and Sack (2002), Fratzscher (2004, 2004) and others that transform broad qualitative references into a $+/-1$ index, or factor procedures by Bernanke et al. (2004) and Gürkaynak et al. (2004) that attempt to identify whether the latent monetary surprise is defined by more than one common component.

\subsection{Exchange rate data and empirical methodology}

Our objective is to examine the high frequency movements in the Swiss 
franc-euro exchange rate to strong and supportive intervention references. Let $I R_{j}$ denote the intervention reference, where $j$ is the date and $\gamma(j)$ gives the sequential order of the intervention references for $\gamma(j)=1, \ldots, J$ number of intervention references. To capture the market response to SNB intervention references, we use intra-daily quotes at ten-minute intervals up to 48 hours. The intra-daily exchange rates, which are taken from the SNB's dealer room, were mid prices between bid and ask quotes. ${ }^{13}$ They were then transformed to percentage returns, by calculating the first difference of the natural logarithm of the mid-price series $\left(\Delta s_{j, t}\right.$ where $t$ denotes the intradaily time for the $\gamma(j)$ th intervention reference).

To evaluate the effectiveness of intervention references, we apply the event study methodology by Fatum and Hutchison (2003) and use the direction criterion to make references about the effectiveness of the SNB's communication strategy at the zero bound. ${ }^{14}$ The test for direction defines a successful inter-

\footnotetext{
${ }^{13}$ We did not find strong evidence that the median spread behaved differently before and after an intervention announcement and versus the median daily spread between 2002 and 2005. Issues of announcement effects and exchange rate volatility are not investigated in this study.

${ }^{14}$ Intervention studies that use the event study approach by Fatum and Hutchison (2003) frequently group several foreign exchange interventions as one event. This is done to avoid simultaneity problems where foreign exchange intervention reacts to exchange rate
} 
vention reference for $I R_{j}$ if $\Sigma_{i=1}^{N} \Delta s_{j, t+i}>0$, where $\Sigma_{i=1}^{N} \Delta s_{j, t+i}=s_{j, t+i}-s_{j, t}$ and $i$ denotes a ten-minute interval for $i=1, \cdots, N$. The direction criterion measures whether, after an intervention reference, the Swiss franc depreciates against the euro.

A non-parametric sign test is used to calculate the likelihood of the direction criterion, see Fatum and Hutchison (2003) for motivation and discussion. We set our choice of the probability of the event to $0.50 .{ }^{15}$ Such a probability is consistent with a random walk without drift for the direction criterion. Further, we use an independence test based on the success ratios to test various hypotheses of sample break or type of intervention reference.

changes. For example, top management often gives the central bank's trading desk the discretion to intervene for several days. In our setup we treat each SNB intervention reference as an event. We assume that the market is reacting to unanticipated news resulting from the SNB intervention references unleashed by a SNB governor. The other two criteria of smoothness and volatility reduction are not considered since they are not frequently mentioned in the zero-bound literature.

${ }^{15}$ We also considered the expected probability defined by the sample. However, this had no bearing on the outcome of the empirical results. For example, there were more appreciating than depreciating changes in the Swiss franc-euro exchange rate (measured by changes in our 10 minute ticks). This meant that the expected probability set at 0.5 is a more stringent hurdle to reject the null. 


\section{Empirical results}

This section presents empirical results on the financial market's response to SNB intervention references. Our main result, presented in the next subsection, shows that the Swiss franc depreciates against the euro for several hours after an SNB intervention reference. ${ }^{16}$ After establishing the robustness of our main result, the empirical analysis focuses on the following questions. Does the communication of SNB intervention references differ from market intervention talk? Is the first reference more important than the subsequent ones? Is the zero interest rate period distinct from the low interest rate period?

\subsection{The market responds to SNB intervention references}

To motivate our empirical focus on SNB intervention references for the post-event (post-reference) period, we begin by plotting exchange rate movements at the time of the SNB intervention references. Figure 2 shows the (ln) change in the Swiss franc-euro exchange rate three hours before and after an SNB reference on exchange rate interventions. All six categories defined in Table 2 are plotted for comparative purposes, despite substantial differences

\footnotetext{
${ }^{16}$ The main results were also performed for the U.S. dollar and the Japanese yen and are consistent with those presented for the euro. These results are available from the authors.
} 
in the number of observations, see Table 2. Intervention references, which are denoted as strong and supportive in Figure 2, show that the exchange rate depreciates just under $0.3 \%$ within an hour and is slow to revert to the level at the time of the announced intervention reference. The same reaction responses to intervention references show no clear evidence that markets are reacting in anticipation of the time stamp of the release - a phenomenon that arises in intervention studies, see Peiers (1997) and Dominguez (2003).

The other intervention references do not have the same reaction profile as the supportive and strong index. Consider the strong/moderate and neglective references. The post-reference and pre-reference reactions are similar in size, but their magnitude is smaller than the exchange rate responses to the supportive and strong index.

Figure 3 plots the significance levels of the sign test that the direction criterion is fulfilled. The event windows range between 10 minutes and 48 hours, where the time of the intervention reference, $\tau_{\gamma(j)}$, is the time stamp of the newswire report and lies in the first 10 minute interval between $t<$ $\tau_{\gamma(j)} \leq t+10$. The evidence from the direction tests finds that the exchange rate does not depreciate immediately after a SNB intervention reference. The direction test is highly significant at the $95 \%$ level after 40 minutes, see the 
profile of the dark line denoted original in Figure $3 .{ }^{17}$ The duration of the significant direction tests is four hours with a brief interruption at the two hour mark. After four hours the level of significance falls frequently below the $95 \%$ level.

Figure 3 also shows the significance levels of direction tests that control for four sources of robustness. The first measure, labelled headline, captures SNB intervention references that mention "SNB intervention" in the headline of the newswire report. Jansen and de Haan (2007) argue that FX traders do not always take the time to read the full newswire report. Their conjecture is that FX traders are more likely to respond to a SNB intervention reference if it is mentioned in the report's headline, otherwise the thrust of the SNB intervention reference is buried in the details. There are 36 headline SNB intervention references.

\footnotetext{
${ }^{17}$ Dominguez and Panthaki (2007) and Fatum and Pederson (2007) argue that FX markets respond faster to scheduled news than non-scheduled news. The latter includes (oral) interventions. This conjecture assumes that scheduled news tends to be better anticipated and more quickly interpreted by the market than non-scheduled news. The lagged response to SNB intervention references is thus consistent with the evidence in Fatum and Pederson (2007). Using intradaily data between 2002 and 2004, they find that the DKK/EUR exchange rate responds about 30 minutes after to the intervention news.
} 
The second measure, labelled macro, controls for important macro information in Switzerland and in the euro area. If a release date for CPI, industrial production, unemployment, GDP, import and export prices and volume, and PPI fall on the same day that a SNB intervention reference was made, then it is dropped from the sample. ${ }^{18}$ This variable allows us to control for whether auxiliary information or SNB intervention references are driving our main result. Dominguez $(2003,2006)$ finds that exchange rates respond stronger to central bank interventions in combination with macroeconomic news than when interventions are executed in the absence of macroeconomic news. There are 56 observations for our macro measure.

The third measure, labelled IR-only, considers whether the newswire report refers only to interventions. Often SNB board members have made intervention references in combination with an assessment of the Swiss and European economy (i.e., forecasts and risks). The ability to separate such information from intervention references is particularly important when interest rates are close to zero. The $I S$-only variable has 38 observations.

\footnotetext{
${ }^{18}$ Although this is a weak test of market sentiment, we also checked the intervention statements for references to carry trades and geopolitical tensions. There were no same-day mentions with intervention references.
} 
The last measure, seasonal adjustment, controls for intra-daily seasonality. Andersen et al. (2003), Dominguez (2006), and others find strong evidence of intra-daily seasonality for foreign exchange rates, and argue that it is necessary to control for this deterministic pattern when modelling exchange rate movements with a GARCH process. To control for intra-daily seasonality, we correct our non-parametric test by first calculating a mean average of $\Delta s_{j, t+i}$ for each 10 minute tick for the 2002 to 2005 period. This mean average is then used in place of the zero restriction for our direction test.

The results in Figure 3 show that different variants of intervention references lead to the same result: the Swiss franc depreciation against the euro is significant at the $90 \%$ level after 40 minutes when an SNB intervention reference is made. The duration of the exchange rate movement depends on the specified measure. The evidence shows that the measures controlling for macro news and seasonality follow the profile of our original index for intervention references for the first four hours. Thereafter, slight differences arise; however, all three series are no longer consistently above the $90 \%$ level. Instead, for the other indexes, headline and only intervention news, the significance levels exhibit some weakness between the second and fourth hour 
and thereafter follow the original index closely. The low number of observations for headline and $I R$-only is an explanation for the slight differences in the results with respect to the original index.

\subsection{SNB intervention references versus market intervention talk}

It is important to distinguish between what is said and who says it. For this reason we examine the role of the SNB intervention references and market intervention talk. The latter references are constructed in the same manner as SNB intervention references. This time, however, the newswire report cites the IMF, OECD, Swiss government officials, and dealers/analysts. The first three agencies called on the SNB to intervene, whereas the analysts speculated whether the SNB would conduct an intervention. ${ }^{19}$ The number of market intervention references is all references minus SNB references in Table 2.

The results of the direction tests in Figure 4 provide strong evidence that the Swiss franc depreciates after an SNB intervention reference. The significance level of rejecting the null is greater than $95 \%$ after 40 minutes. This

\footnotetext{
${ }^{19}$ We only focus on whether the two sorts of references have different effects, because the amount of interaction between the two is limited. SNB intervention references and market intervention references do not fall on the same day.
} 
result is also supported by evidence from the success ratios (i.e., the number of times $\sum_{i=1}^{N} \Delta s_{j, t+i}>0$ divided by the number of intervention reference). They are almost always above $60 \%$, see Figure 4 .

The evidence for market intervention talk is at odds with the empirical results for SNB intervention references. The level of significance of rejecting the null hypothesis that the Swiss franc does not depreciate after a market intervention reference is never above $90 \%$ after 20 minutes. This evidence is also supported by the weaker success ratios compared to those of the intervention references. We interpret the evidence from Figure 4 as follows. The source of the intervention references matters. The FX market responds only to SNB intervention references.

\subsection{Is the effect of the first announcement stronger?}

This question is motivated by the observation in Fischer and Zurlinden (1999) that FX markets react stronger to the first SNB foreign exchange intervention than to the following interventions on the same day. A further aspect is the observation that repetition is a problematic feature in empirical analysis based on newswire reports. Recurring reports increase the number of observations, yet it is unclear whether markets respond to older reports that restate the same information in a different manner. To avoid interpre- 
tation problems of identifying repetitive cases, we examine the influence of the first SNB intervention reference for a given day versus SNB intervention references that follow on the same day. We use an independence test, $\chi_{(1)}^{2}$ distributed, to examine the null hypothesis that the success ratios of the first SNB intervention reference equal the success ratios of the following SNB intervention references on the same day. The success ratios for the direction criterion are based on the exchange rate movements that span the 10 minute to 6 hour range after an intervention reference is made.

The independence tests find that the first SNB references behave similar to the repeated references. The significance levels of rejecting the null are shown in the second column of Table 3. The significance levels always lie below $90 \%$ for the different event windows, except for two instances. We interpret this evidence to mean that repetitive newswire reports do not diminish the impact of SNB intervention references.

3.4 Are references more important when interest rates are zero?

Next, we ask whether a communication policy of intervention references is equally effective when interest rates are zero as opposed to when they are near their lower bound? Our sample covers a 16-month period when the SNB's operating instrument stood at $0.11 \%$, see Figure 1a. Although the 
SNB never officially declared the 2003:3 to 2004:6 episode as one of zero interest rates, we define this for our purposes as the period of zero bound. Again, we use an independence test to test whether the period from 6.3.2003 to 16.6.2004 differs from the rest of the 2002 to 2005 sample. $^{20}$

The evidence based on the independence tests is unable to reject the null hypotheses of sample equality. Column three of Table 3 provides significance levels of rejecting the null that the success ratios of the two samples are the same for the direction criterion. The significance level is greater than $90 \%$ for the direction criterion in only one instance (i.e., after six hours). Our interpretation of the evidence is that the exchange rate response to SNB communication on FX interventions was equal for the low and zero interest rate environment.

\section{Conclusions}

Our objective is to examine the financial market's response to SNB intervention references at the zero bound. Our analysis of the SNB's practice

\footnotetext{
${ }^{20}$ During our non-zero interest rate period, the repo rate fluctuated between $0.2 \%$ and $1.57 \%$ with an average of $0.83 \%$. The number of observations during the zero interest rate period is 48 as opposed to 41 observations for the non-zero period. A simple sample split at 1:1:2004 would have resulted in only 16 observations in the later period.
} 
of communicating unconventional policies makes two contributions. First, the narrower definition of verbal interventions should reduce the subjectivity of index construction in previous studies on central bank communication. We consider a unique episode that focuses on strongly worded statements referring to non-sterilized interventions. Second, the experience of Swiss communication policy expands the empirical literature on the zero bound, which has focused solely on the United States and Japan. This case study at the zero bound is unique in that the SNB pursued an open communication policy in that it made numerous references to foreign exchange interventions as a policy option.

Our empirical results based on the direction criterion using intra-daily data for the period 2002 to 2005 provide strong evidence that strongly worded references are capable of generating a market response that leads to a depreciation of the Swiss franc for a few hours. This result is robust to controls for seasonality and multiple news arrivals. The empirical evidence also supports a communication strategy where central bankers talk frequently to markets and well before interest rates reach the lower bound. 


\section{References}

Anderson, T. Bollerslev, T. Diebold, F., Vega, C., 2003. Micro effects of macro announcements: Real time price discovery in foreign exchange, American Economic Review 93(1), 38-62.

Baltensperger, E., Fischer, A. M., and Jordan, T. J., 2007. Goal independence and inflation targeting, European Journal of Political Economy 23, 88-105.

Beine, M., Janssen, G., and Lecourt, C., 2004. Should central bankers talk to the FX markets?, mimeo.

Bernanke, B. S., 2002. Deflation: Making sure it doesn't happen here, Remarks by Governor B. S. Bernanke, Before the National Economists Club, Washington, D.C. November 21, 2002.

Bernanke, B. S. and Reinhart, V. R., 2004. Conducting monetary policy at very low short-term interest rates, American Economic Review Papers and Proceedings 94(2), 85-90.

Bernanke, B. S., Reinhart, V. R., and B. Sack, B., 2004. Monetary policy alternatives at the zero bound: An empirical assessment, Brookings Papers on Economic Activity 2, 1-95.

Boukus, E. and Rosenberg, J. V., 2006. The information content of FOMC minutes, mimeo.

Chiu, P., 2003. Transparency versus constructive ambiguity in foreign exchange intervention, BIS Working Papers No. 144.

Clouse, J., Henderson, D., Orphanides, A., Small, D., and Tinsley, P., 2000. Monetary policy when the nominal short-term interest rate is zero, mimeo.

Dominguez, K. M. E., 2006. When do central bank interventions influence intra-daily and longer-term exchange rate movements?, Journal of International Money and Finance 25(7), 1051-1071.

Dominguez, K. M. E., 2003. The market microstructure of central bank intervention, Journal of International Economics 59(1), 25-45.

Dominguez, K. M. E. and Panthaki, F., 2007. The influence of actual and unrequited interventions, International Journal of Finance and Economics $12(2), 107-143$.

Eggertsson, G. and Woodford, M., 2003. The zero bound on interest rates and optimal monetary policy, Brookings Papers on Economic Activity (1), 139-233. 
Fatum, R. and Pedersen, J., 2007. Real-Time Effects of Central Bank Intervention in the Euro Market, SCCIE Working Paper No. 07-07.

Fatum, R. and Hutchison, M. M., 2003. Is foreign exchange intervention effective after all? An event study approach, Economic Journal 113, 390411.

Fatum, R. and Hutchison, M. M., 2002. ECB foreign exchange intervention and the euro: institutional framework, news, and intervention, Open Economies Review 13(4), 413-425.

Fischer, A. M., 2006. On the inadequacy of newswire reports for empirical research on foreign exchange interventions, Journal of International Money and Finance 25(8), 1226-1240.

Fischer, A. M., 2003. Measurement error and the profitability of interventions: A closer look at SNB transactions data, Economics Letters 81(1), $137-142$.

Fischer, A. M., 2002. Fluctuations in the Swiss franc: What has changed since the euro's introduction?, Journal of Public Policy 22(2), 143-160.

Fischer, A. M. and Zurlinden, M., 1999. Exchange rate effects of central bank interventions: An analysis of transaction prices, Economic Journal 109, 662676.

Fratzscher, M., 2006. On the long-term effectiveness of exchange rate communication and interventions, Journal of International Money and Finance $25(1), 146-167$.

Fratzscher, M., 2005. Strategies of exchange rate policy in G3 economies, Economics Letters 89, 68-74.

Ito, T., 2004. Inflation targeting and Japan: Why has the Bank of Japan not adopted inflation targeting?, NBER Working Paper 10818.

Ito, T. and Mishkin, F. S., 2004. Two decades of Japanese monetary policy and the deflation problem, NBER Working Paper 10878.

Gürkaynak, R. S., Sack, B., and Swanson, E. T., 2005. Do actions speak louder than words? The response of asset prices to monetary policy actions and statements, International Journal of Central Banking 1(1), 55-94.

Jansen, D. J. and de Haan, J., 2005. Talking heads: The effects of ECB statements on the euro-dollar exchange rate, Journal of International Money and Finance 24(2), 343-361.

Jansen, D. J. and de Haan, J., 2007. Were verbal efforts to support the euro effective? A high-frequency analysis of ECB statements, European Journal of Political Economy 23(1), 245-259. 
Natal, J. M., 2004. Deflation and deflationary traps: The situation in Switzerland, Schweizerische Zeitschrift für Volkswirtschaft und Statistik 140(1), 127-170.

Neely, C., 2005. An analysis of recent studies of the effect of foreign exchange intervention, Federal Reserve Bank of St. Louis Review 87(6), 685-717.

Payne, R. and Vitale, P., 2003. A transaction level study of the effects of central bank intervention on exchange rates, Journal of International Economics 61(2), 331-352.

Pasquariello, P., 2007. Informative trading or just noise? An analysis of currency returns, market liquidity, and transaction costs in proximity of central bank interventions, Journal of Financial Markets, 10(2), 107-143.

Peiers, B., 1997. Informed traders, intervention, and price leadership: A deeper view of the microstructure of the foreign exchange market, Journal of Finance 52(4), 1589-1614.

Rich, G., 2000. Switzerland and the euro, Atlantic Economic Journal 28, 309-311.

Rich, G., 1990. Exchange rate management under floating exchange rates: A skeptical view, Journal of Banking and Finance 14, 993-1021.

Sarno, L. and Taylor, M., 2001. Official intervention in the foreign exchange market: Is it effective and, if so, how does it work, Journal of Economic Literature 39(3), 839-68.

Svensson, L. O., 2001. The zero bound in an open economy: A foolproof way of escaping from a liquidity trap, Monetary and Economic Studies, vol. 19. no. S-1, 277-312.

Vitale, P., 2006. A critical appraisal of recent developments in the analysis of foreign exchange intervention, CEPR Working Paper No. 5729. 
Table 1: SNB references on FX interventions and their classification

\begin{tabular}{|c|c|}
\hline Neglective & Examples of $S N B$ references that do not encourage the use of $F X$ interventions \\
\hline strong & $\begin{array}{l}\text { "Asked whether the SNB could intervene on foreign exchange markets to influence the franc rate, Roth said that it had } \\
\text { been some } 12 \text { years since the SNB had intervened and said that open market interventions risked disturbing the } \\
\text { policy message." }(14.01 .2002,11: 12)\end{array}$ \\
\hline moderate & $\begin{array}{l}\text { "We have renounced to intervene in the foreign-exchange market, not as a matter of principle, but in the opinion that } \\
\text { this instrument is linked to high uncertainties and should be used only in exceptional cases, } \\
\text { Gehrig said." (18.06.2002, 11:30 }\end{array}$ \\
\hline weak & $\begin{array}{l}\text { "Hildebrand went on: The stable rate of the franc to the euro, in particular, has meant that monetary conditions are } \\
\text { very accommodative. This is not hindering the economic recovery but is supporting it. Currency market interventions } \\
\text { are not an issue now, but they remain an option." }(28.04 .2004,08: 46)\end{array}$ \\
\hline Supportive IT & Examples of $S N B$ references that encourage the use of $F X$ interventions \\
\hline weak & $\begin{array}{l}\text { "Roth ruled out any substantial intervention to weaken the Swiss franc against the dollar, as some exporters are } \\
\text { asking. However, Roth reiterated the SNB would intervene in the foreign exchange market if the Swiss franc strengthened } \\
\text { too much against the euro, the currency of Switzerland's main trading partners." (26.06.2003, 10:01) }\end{array}$ \\
\hline moderate & $\begin{array}{l}\text { "Roth reiterated in the interview the SNB could intervene should a spike in the franc endanger the economy." } \\
(15.04 .2003,16: 52)\end{array}$ \\
\hline strong & $\begin{array}{l}\text { "Given that we no longer have any significant room for manoeuvre on interest rates, we will if necessary intervene in } \\
\text { currency markets in order to counter an unwanted rise, Gehrig said." }(26.03 .2003,20: 04) \text { " } \\
\text { "We have no limits in terms of the liquidity we can create, he said. Foreign exchange market interventions, which we } \\
\text { can use in certain situations, also belong to our tool kit, Roth said." }(24.08 .2002,11: 10)\end{array}$ \\
\hline
\end{tabular}


Table 2: Frequency of SNB intervention references

\begin{tabular}{|l|c|c|c|}
\hline & \multicolumn{3}{|c|}{ period 2002 - 2005 } \\
\hline scale & all references & SNB references & first SNB references \\
\hline strong SIR & 137 & 89 & 69 \\
moderate SIR & 15 & 4 & 3 \\
weak SIR & 4 & 1 & 1 \\
weak NIR & 13 & 11 & 7 \\
moderate NIR & 5 & 4 & 2 \\
strong NIR & 3 & 112 & 84 \\
\hline total & 177 & 3 & 2 \\
\hline
\end{tabular}

Notes: All references fall within trading hours. SIR denotes supportive intervention references, whereas NIR denotes neglective intervention references. First SNB references denote no repetitive references. All references are SNB intervention references and market intervention references. 
Table 3: Independence tests of SNB intervention references

\begin{tabular}{|l|c|c|}
\hline Time window & First versus following references & low versus zero interest rate period \\
\hline $10 \mathrm{~min}$ & 0.042 & 0.336 \\
$20 \mathrm{~min}$ & 0.259 & 0.021 \\
$30 \mathrm{~min}$ & 0.202 & 0.064 \\
$40 \mathrm{~min}$ & 0.175 & 0.067 \\
$50 \mathrm{~min}$ & 0.339 & 0.097 \\
$60 \mathrm{~min}$ & 0.479 & 0.449 \\
$70 \mathrm{~min}$ & 0.557 & 0.264 \\
$80 \mathrm{~min}$ & 0.223 & 0.009 \\
$90 \mathrm{~min}$ & 0.223 & 0.041 \\
$100 \mathrm{~min}$ & 0.012 & 0.029 \\
$110 \mathrm{~min}$ & 0.406 & 0.011 \\
$120 \mathrm{~min}$ & 0.060 & 0.029 \\
$130 \mathrm{~min}$ & 0.031 & 0.097 \\
$140 \mathrm{~min}$ & 0.953 & 0.029 \\
$150 \mathrm{~min}$ & 0.953 & 0.449 \\
$160 \mathrm{~min}$ & 0.498 & 0.262 \\
$170 \mathrm{~min}$ & 0.498 & 0.575 \\
$180 \mathrm{~min}$ & 0.498 & 0.575 \\
$240 \mathrm{~min}$ & 0.309 & 0.603 \\
$300 \mathrm{~min}$ & 0.816 & 0.097 \\
$360 \mathrm{~min}$ & 0.176 & 0.961 \\
\hline Notes: Values denote levels of significance of rejecting the null for the direction, smoothness, & \\
\hline
\end{tabular}

and volatility criteria. The null hypotheses are the equality of the success ratios between

first and following SNB intervention references and the low versus zero interest rate sample. 
Figure 1a:

SNB Intervention reference index and short-term interest rates

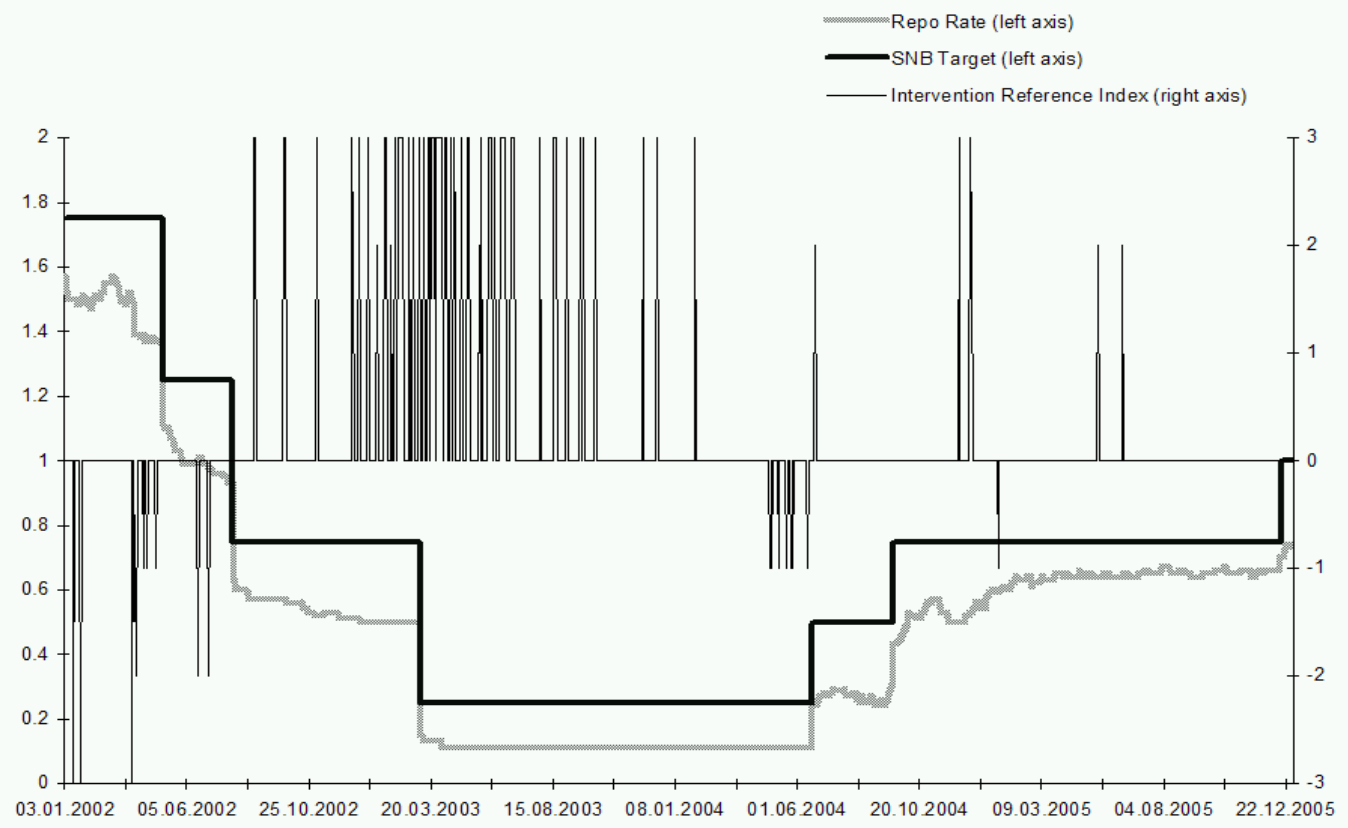


Figure 1b:

SNB Intervention reference and Swiss franc/euro exchange rate

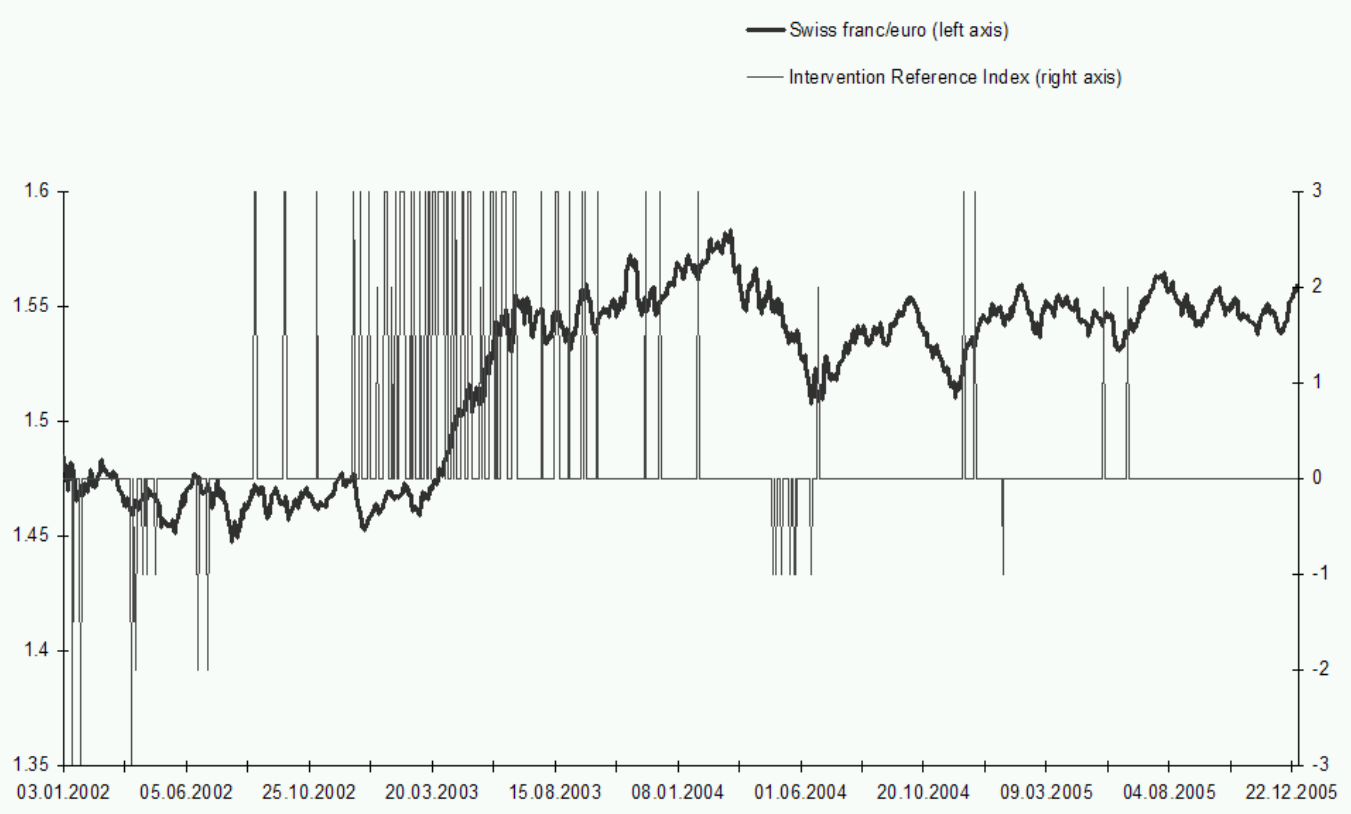


Figure 2:

Swiss franc/euro exchange rate movements before and after SNB references

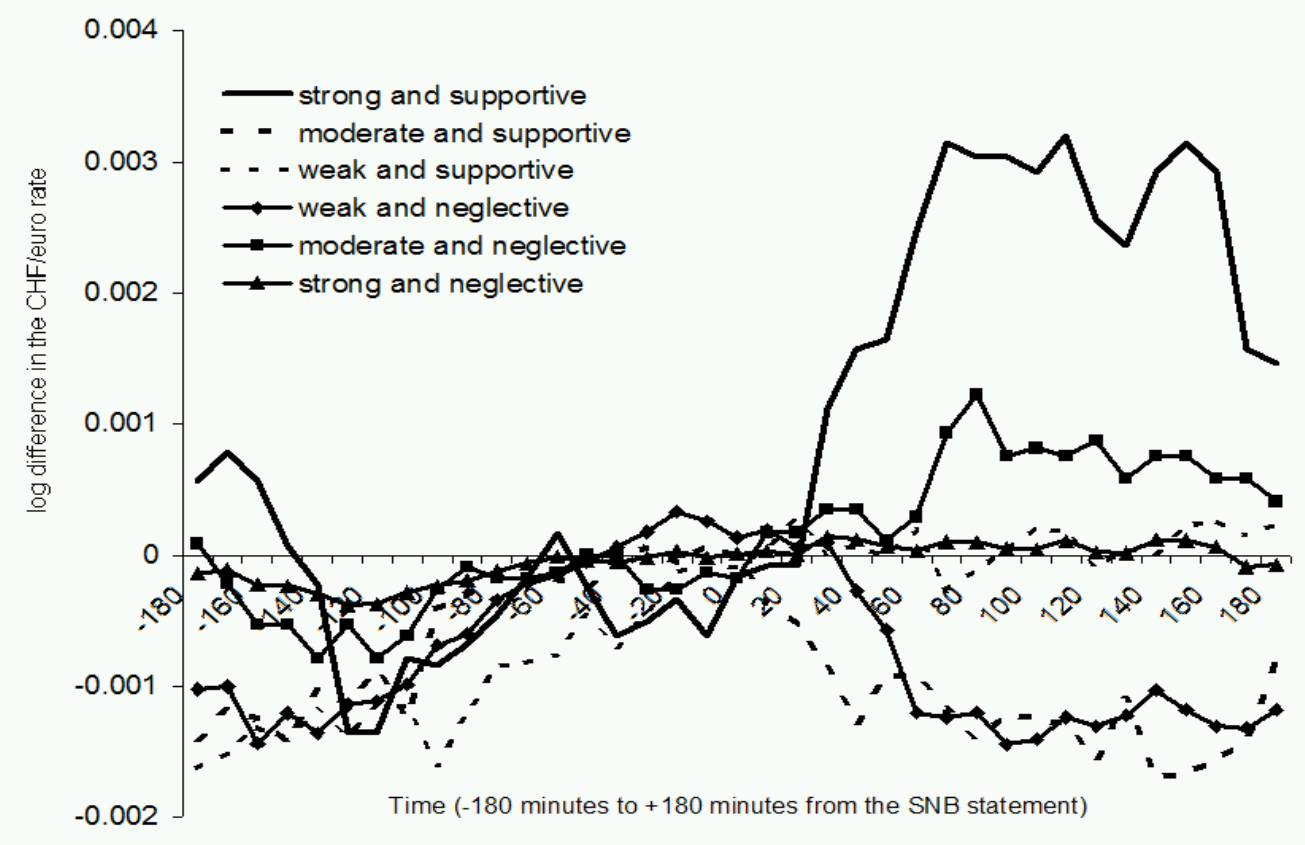


Figure 3:

Sign tests for direction criterion with four different controls

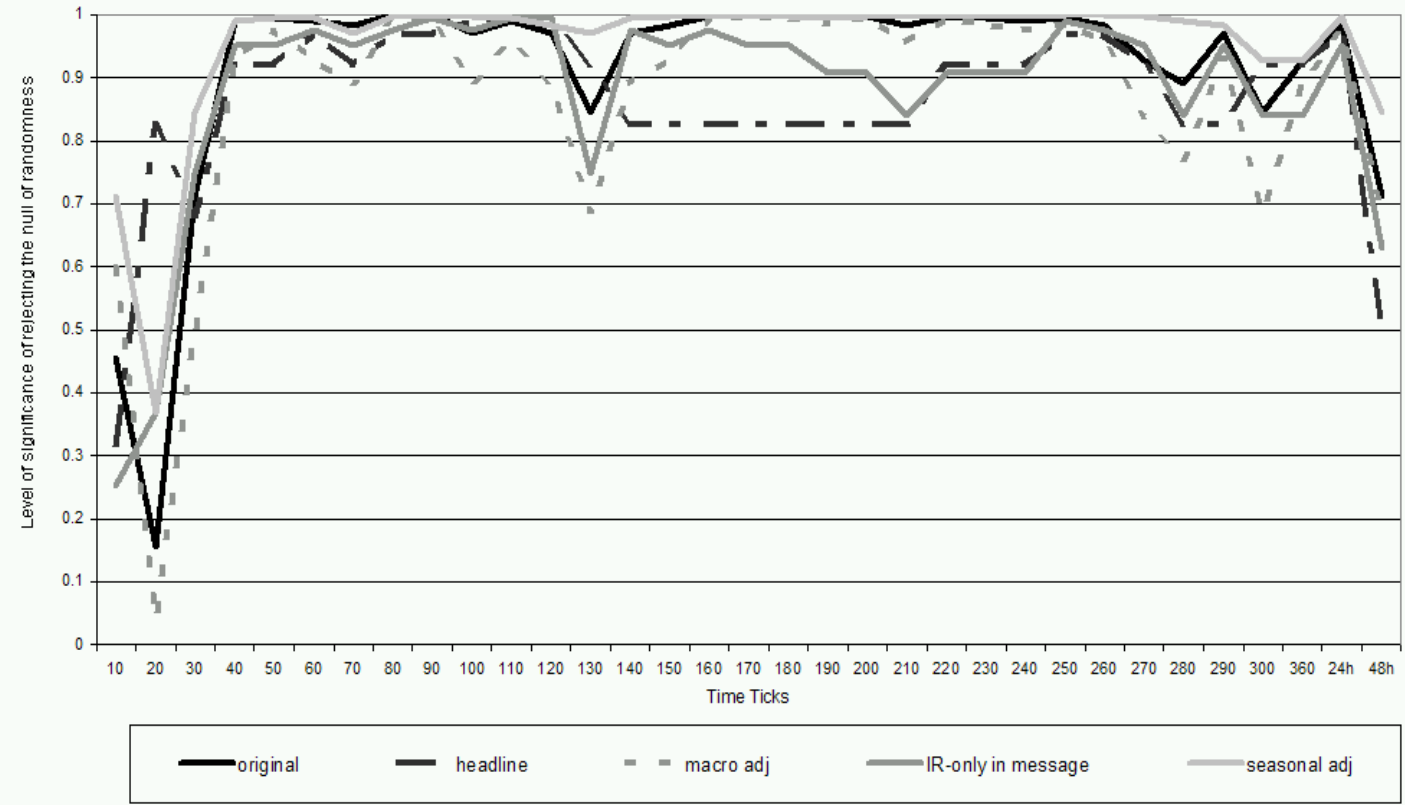


Figure 4:

Sign tests for direction criterion: SNB versus market talk

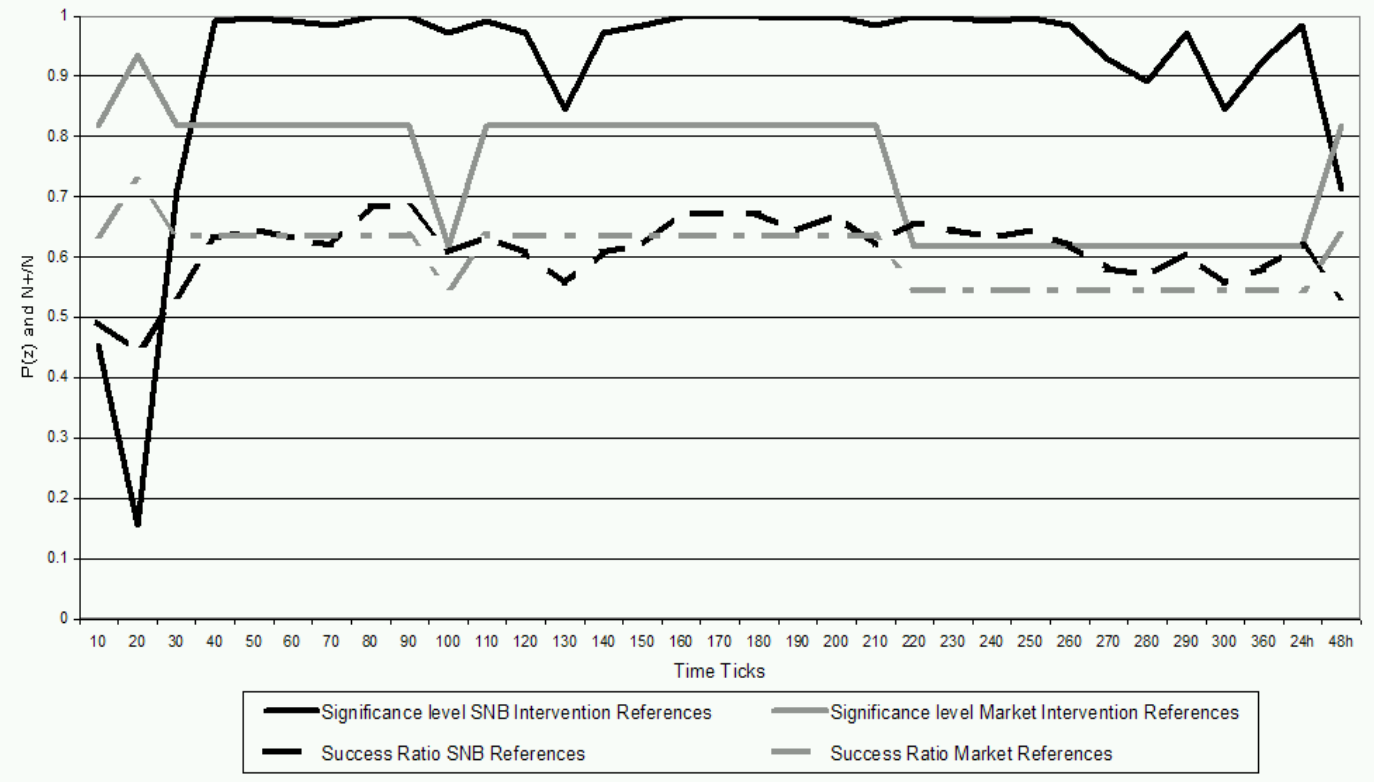




\section{Swiss National Bank Working Papers published since 2004:}

2004-1 Samuel Reynard: Financial Market Participation and the Apparent Instability of Money Demand

2004-2 Urs W. Birchler and Diana Hancock: What Does the Yield on Subordinated Bank Debt Measure?

2005-1 Hasan Bakhshi, Hashmat Khan and Barbara Rudolf: The Phillips curve under state-dependent pricing

2005-2 Andreas M. Fischer: On the Inadequacy of Newswire Reports for Empirical Research on Foreign Exchange Interventions

2006-1 Andreas M. Fischer: Measuring Income Elasticity for Swiss Money Demand: What do the Cantons say about Financial Innovation?

2006-2 Charlotte Christiansen and Angelo Ranaldo: Realized Bond-Stock Correlation: Macroeconomic Announcement Effects

2006-3 Martin Brown and Christian Zehnder: Credit Reporting, Relationship Banking, and Loan Repayment

2006-4 Hansjörg Lehmann and Michael Manz: The Exposure of Swiss Banks to Macroeconomic Shocks - an Empirical Investigation

2006-5 Katrin Assenmacher-Wesche and Stefan Gerlach: Money Growth, Output Gaps and Inflation at Low and High Frequency: Spectral Estimates for Switzerland

2006-6 Marlene Amstad and Andreas M. Fischer: Time-Varying Pass-Through from Import Prices to Consumer Prices: Evidence from an Event Study with Real-Time Data

2006-7 Samuel Reynard: Money and the Great Disinflation

2006-8 Urs W. Birchler and Matteo Facchinetti: Can bank supervisors rely on market data? A critical assessment from a Swiss perspective

2006-9 Petra Gerlach-Kristen: A Two-Pillar Phillips Curve for Switzerland

2006-10 Kevin J. Fox and Mathias Zurlinden: On Understanding Sources of Growth and Output Gaps for Switzerland

2006-11 Angelo Ranaldo: Intraday Market Dynamics Around Public Information Arrivals

2007-1 Andreas M. Fischer, Gulzina Isakova and Ulan Termechikov: Do FX traders in Bishkek have similar perceptions to their London colleagues? Survey evidence of market practitioners' views 
2007-2 Ibrahim Chowdhury and Andreas Schabert: Federal Reserve Policy viewed through a Money Supply Lens

2007-3 Angelo Ranaldo: Segmentation and Time-of-Day Patterns in Foreign Exchange Markets

2007-4 Jürg M. Blum: Why ‘Basel II’ May Need a Leverage Ratio Restriction

2007-5 Samuel Reynard: Maintaining Low Inflation: Money, Interest Rates, and Policy Stance

2007-6 Rina Rosenblatt-Wisch: Loss Aversion in Aggregate Macroeconomic Time Series

2007-7 Martin Brown, Maria Rueda Maurer, Tamara Pak and Nurlanbek Tynaev: Banking Sector Reform and Interest Rates in Transition Economies: Bank-Level Evidence from Kyrgyzstan

2007-8 Hans-Jürg Büttler: An Orthogonal Polynomial Approach to Estimate the Term Structure of Interest Rates

2007-9 Raphael Auer: The Colonial Origins Of Comparative Development: Comment. A Solution to the Settler Mortality Debate

2007-10 Franziska Bignasca and Enzo Rossi: Applying the Hirose-Kamada filter to Swiss data: Output gap and exchange rate pass-through estimates

2007-11 Angelo Ranaldo and Enzo Rossi: The reaction of asset markets to Swiss National Bank communication

2007-12 Lukas Burkhard and Andreas M. Fischer: Communicating Policy Options at the Zero Bound 
Swiss National Bank Working Papers are also available at www.snb.ch, section Publications/Research Subscriptions or individual issues can be ordered at Swiss National Bank, Fraumünsterstrasse 8, CH-8022 Zurich, fax+41 4463181 14, E-mail library@snb.ch 